\title{
Congestion, Tolls, and the Economic Capacity of a Waterway*
}

Lester B. Lave

Carnegie-Mellon University

\section{Joseph S. DeSalvo}

The RAND Corporation

One externality which has received little attention from economists is that connected with congestion (a recent treatment is Strotz, 1965). An increase in the utilization of a facility can result in longer waiting time or in a less appealing service. For example, an increased number of tows on a waterway can give rise to greater delays at locks; a larger crowd at a beach can lead to a lower satisfaction for each "customer." The former case, which involves production, is particularly complex. Here, delay is caused either by the random arrival of customers or by a random service (production) rate. Serving tows at a lock is analogous to serving shoppers at a supermarket checkout stand. Similar problems occur with respect to allocating docking facilities in a port, runways and terminals in an airport, land to streets in an industrial park, and machines in a job shop. ${ }^{1}$

Three questions are intertwined in these examples. When the physical capacity of a system is fixed, one question involves the determination of economic capacity; for example, how many customers should be served if the addition of a customer will cause external effects on all other customers? The second question concerns the long run; if the size of the facility can be altered, how much should the physical capacity be expanded to attain

* This research was performed at the Econometric Research Center, Northwestern University, under a contract with the U.S. Army Corps of Engineers. The views expressed are those of the authors and do not necessarily represent those of the Army or Northwestern University. The authors are indebted to our colleagues on the Waterways Projects for comments, especially Leon N. Moses, Robert H. Strotz, and James P. Stucker; we also wish to acknowledge helpful criticism from Otto Davis, Michael Lovell, and Judith Lave.

${ }^{1}$ The class of problems analyzed here would be extremely simple examples of production scheduling problems. 
economic efficiency? The third question concerns the amount of service given to a customer: How large a patch of beach should be allocated to one consumer? How large a tow should be permitted on a waterway? The first and third problems might be handled by a system of taxes and subsidies designed to equate private to social cost. The second problem might be handled via a benefit-cost analysis of the expansion decision.

These three questions arise whenever congestion occurs; our proposed solutions are relevant to all these circumstances. If the facility is publicly owned, a government agency acts as decision maker; if the congestion occurs at a facility (such as a machine) owned by a firm, the firm acts as decision maker. Problems arising from congestion are widespread; our analysis and proposed solutions are quite general. In order to focus the analysis and provide a concrete illustration, we develop the argument for inland waterway transportation.

The basic issues can be illustrated by considering a crowded airport. The number of airplanes desiring to use a runway (to takeoff or land) each minute is random (note that the demand changes during the day). It is always possible for an airline to schedule an additional flight, although congestion would be increased. Most of the increased congestion is experienced as an effect external to the additional flight; it is seen as a result of increased utilization and as little affected by any single flight. Even when the congestion is great, the airline is not motivated to consider the effect on other airlines of adding a flight. In order to internalize congestion (thereby rationalizing the airline's decision to add a flight), a toll or regulatory scheme is necessary. Eventually, congestion will increase to the point where it is socially optimal to expand airport capacity. As is the case for waterways, the market does not provide a mechanism to determine when and how much expansion is optimal. The airlines have no direct voice in the decision to expand the facility. Indeed, they are even motivated to overstate the cost of congestion, since they benefit from expansion but bear little of the cost. Finally, the existence of congestion and tolls will lead airlines to modify their fleet.

\section{A Physical Measure of Capacity}

The inland waterways system in the United States contains 25,000 miles of navigable rivers and canals. To serve such functions as aiding navigation, dams have been built at intervals on most of these waterways. A tow, consisting of a towboat pushing a number of barges, traverses the dam by means of a lock. The tow typically moves at a speed of 5 to 10 miles per hour in the waterway, waits for its turn to enter a lock, is locked through, and proceeds toward the next lock. In many cases, the tow is so large that it cannot fit into the lock; two or three passes (procedures called double and triple locking) might be required. 
If one watched a waterway, one would see an occasional tow steaming between locks and a number of tows queued at each lock awaiting service. If the number of tows were increased, the principal effect would be an increase in the number of tows queued at locks. Bottlenecks determine capacity, and it is the lock which determines the capacity of a waterway. ${ }^{2}$

The physical capacity of a waterway might be measured in terms of the number of barges that could be locked through in the course of a year $(C)$. These barges arrive in tows, and, as will be described later, the rate at which tows can be served $[\mu(b)]$ is inversely related to the number of barges in the tow $(b)$. The relationship is assumed to have the shape shown in Figure 1. Thus, the number of tows that could be served in a year $(K)$ depends on the size of each tow. If all tows were of the same size, $K$ could be calculated from equation (1),

$$
K=\frac{8,760}{1 / \mu(b)}=8,760 \mu(b)
$$

where 8,760 is the number of hours in a year, and $1 / \mu(b)$ is the service time for a tow of $b$ barges (measured in hours). Assuming all tows have $b$

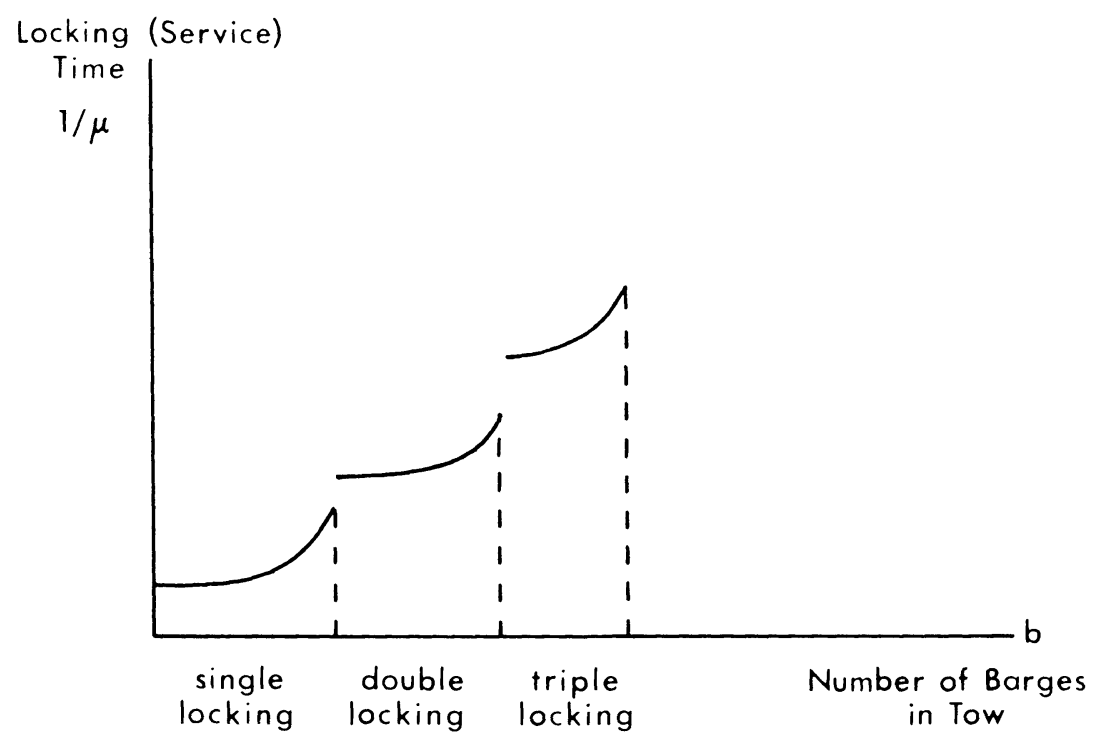

Fig. 1.- Service time as a function of the size of tow

\footnotetext{
${ }^{2}$ More precisely, a waterway might be described as a serial processing system since a tow must traverse the waterway in prescribed order to move from origin to destination. Under these conditions, the capacity of a system is determined by the capacity of the slowest serving facility (the narrowest bottleneck). For a waterway, it is the lock which determines capacity. Throughout this paper, whenever we speak of expanding the capacity of a waterway we will be referring to expanding the physical capacity (service rate) of locks.
} 


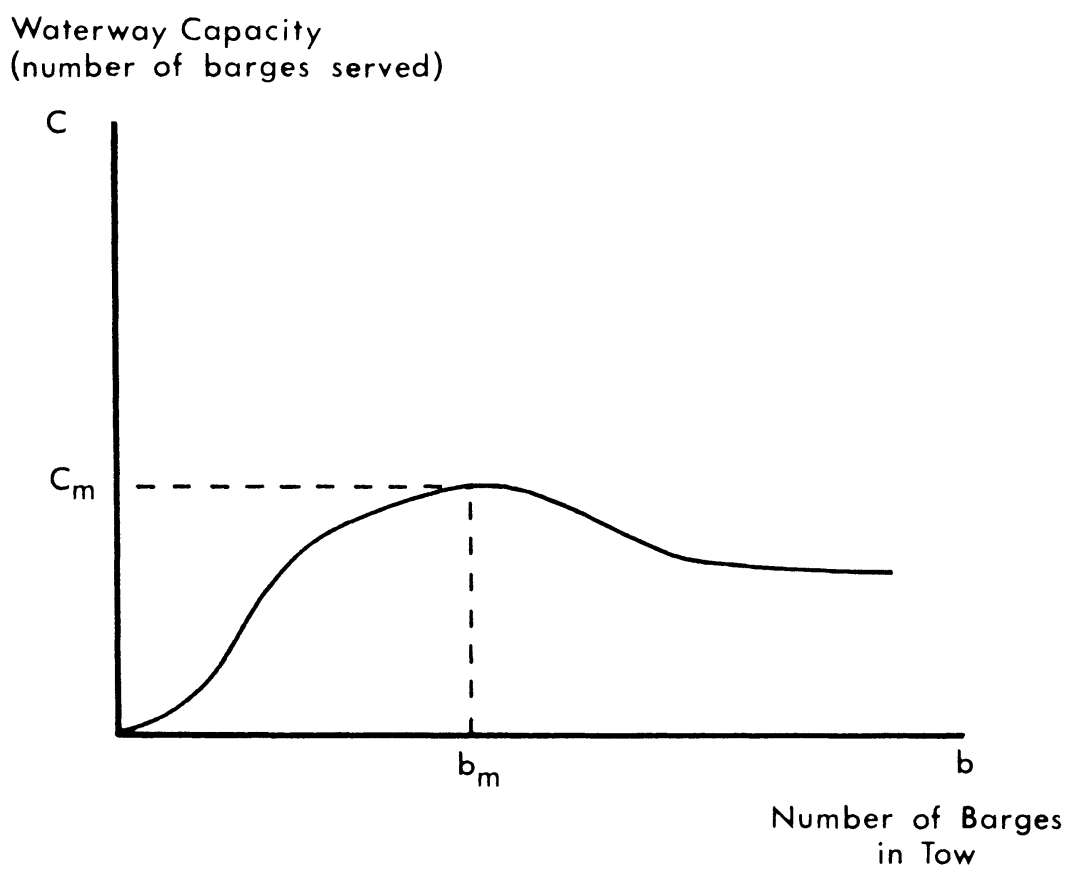

FIG. 2.-Waterway capacity as a function of the size of tow

barges, the number of barges that could be serviced in a year is given in equation (2):

$$
C=K b .
$$

Capacity as a function of the number of barges in each tow is graphed in Figure 2.

Equation (2) and Figure 2 characterize a physical measure of the capacity of a waterway. ${ }^{3}$ They imply that as many as $C_{m}$ barges could be served. However, there are difficulties precluding a lock from attaining this rate of output. Equations (1) and (2) are based on the assumption that tows are of uniform size (and thus that service time is uniform). Since this assumption does not obtain in practice, one would never observe $C_{m}$. Moreover, even if the average tow consisted of $b_{m}$ barges (the number required to produce $C_{m}$ ), this maximum would not be attained because of the variation about the average size and the fact that service time is not proportional to $b$. A more important difficulty is associated with another assumption which is implicit in this analysis.

Equation (2) is based on the implicit assumption that there is always a tow ready for service when the previous tow is through the lock. Thus tows must be scheduled to arrive at the proper time, or extremely long

${ }^{3}$ See, for example, the analysis in Bottoms (1966). 
delays would be encountered. Tows are not, and could not easily be, scheduled to arrive at a lock within a few hours of a target time. Arrival rates depend on the speed of the tow, its origin, where it stopped to pick up or drop off barges, and delays due to weather or previous waits at locks. Whatever pattern may have existed in departing from port, these factors make the arrival of a tow at a lock an unpredictable event.

It is extremely costly for a tow to be kept waiting. The capital (including cargo) and labor cost of keeping a 3,000-horsepower towboat and fifteen barges waiting is on the order of $\$ 100-\$ 200$ per hour. ${ }^{4}$ Substantial waiting time would raise the cost of waterway transportation considerably. These cost increases would be passed on in the form of higher shipping rates and would result in a lower amount of waterway transportation being demanded. Congestion is currently an important factor in determining the costs of barge transportation.

Since tows cannot be scheduled and it is costly to keep them waiting, one cannot expect that a tow will always be awaiting service at a lock. The physical capacity of a waterway, as shown in equation (2), is an inappropriate measure from an economic standpoint and would never be approached in actual operations. However, this physical measure is an input into the analysis of economic capacity. To determine the economic capacity of a waterway, one must also consider the randomness of arrivals and service times and the varying size of tows. Before constructing the analysis, additional discussion of locking procedures and a formal analysis of the time required for lock service under conditions of random arrivals and service times is necessary. ${ }^{5}$

\section{An Analysis of Locking Time}

For a tow to traverse a lock, five operations are involved. (1) The tow "arrives" and awaits permission to approach the lock (previous tows must be serviced first). (2) When permission is received, the tow approaches the lock and maneuvers into the chamber. (3) The lock now goes into operation and is filled or emptied (depending on the direction of the movement). (4) Locking completed, the tow must maneuver out of the lock and into the channel. (5) If the tow is large, operations (2), (3), and (4) must be repeated to "double lock" the remainder of the tow. When

${ }^{4}$ The size of the towboat is assumed to be optimal for pushing fifteen barges; such a towboat costs about $\$ 750,000$ and has a life of ten to fifteen years. Barges cost about $\$ 80,000$ and have a life of twenty years. If half the barges were full, the tow would carry 11,000 tons of cargo. These tows carry a crew of about twelve men and thus have an hourly wage bill of close to $\$ 100$.

${ }^{5}$ To continue the analogy with airports, the service rate (landing and takeoff rate) depends on the speed and landing characteristics of airplanes and the nature of airport guidance equipment. Takeoff delays, different routings, and weather peculiarities cause the demand for runways to be random each minute. 
double locking is required, the operation is slowed more than proportionally since the tow must be disassembled, part of it pulled mechanically into and out of the lock, the lock must make one cycle empty, and the tow must be reassembled on the other side. ${ }^{6}$ Tows coming from the opposite direction are not permitted to enter the lock until the first tow has finished service. (Locking time is identical whether the tow is headed up or down stream.)

Operations (1) and (3) will be independent of the number of barges in the tow; the other operations will be directly related to tow size. One might translate this description into graphic form as in Figure 1, which shows the time taken to service a tow as a function of tow size (waiting time is excluded).

We now model the locking process (operations [1]-[5]) in order to predict the average total locking time (waiting plus service time). This model has been estimated using data collected on the Illinois waterway (five locks over a period of two years); the model fits the data extremely well (see DeSalvo and Lave, 1968).

The number of tows arriving at a lock within an interval of time of duration $t$ is given by a Poisson distribution with parameter $\lambda t$, where $\lambda$ is the arrival rate per unit $t$. (The arrival rate does not vary over the day, although variation could be accommodated in the model.) In addition, the number of tows serviced in an interval of duration $t$ is also assumed to be Poisson distributed with parameter $\mu t$, where $\mu$ is the service rate of tows per unit $t{ }^{7}$ Given $\lambda$ and $\mu$ and the assumption of Poisson arrivals and services, the expected waiting time in queue $T_{L q}$ and total locking time $T_{L}$ (for a tow) are derived in queuing theory; they are shown in equation (3):

$$
\begin{aligned}
T_{L q} & =\frac{\lambda}{\mu(\mu-\lambda)} ; \\
T_{L} & =\frac{1}{\mu}+T_{L q}=\frac{1}{\mu-\lambda} .
\end{aligned}
$$

Thus, total locking time is the sum of waiting time and service time.

The analysis is easily exiended to take account of the fact that a waterway generally contains a series of locks rather than a single one. Under the above assumptions, the arrival of tows at each lock is random. As long as locks operate independently and the arrival rate is less than the service rate, the total locking time (for a tow) will merely be the sum of total locking times at each facility. ${ }^{8}$

\footnotetext{
${ }^{6}$ Only in extreme circumstances are additional towboats used to speed the locking process. Since the cost (per hour) of a towboat is quite high, it is rare that an additional towboat would speed locking enough to be economical.

${ }^{7}$ In queuing theory these assumptions are characterized as a Poisson arrival rate and an exponential service time. See, for example, Morse (1958).

${ }^{8}$ For a discussion of sequential serving facilities and a proof of this theorem, see Hunt (1956).
} 


\section{The Optimal Rate of Waterway Utilization}

Many companies compete for transportation business on the waterway. To each company, congestion is a cost on which it has little effect. Each company is motivated to consider only the waiting time that its own tows encounter. Most of the increased congestion is external to a tow and so will not be considered. In this section, we will calculate the social cost of adding a tow to existing traffic.

Suppose that a total tonnage (upstream or downstream) of $P$ per year is to be moved over a particular waterway. Suppose further that the average load of a tow is $A$ tons. Then $P / A$ full tows must traverse the waterway (and each lock). Let $p$ be the proportion of full tows that have an empty backhaul, $0<p<1$. Then the total number of tows traversing the waterway in a year is $K=(1+p) P / A$. Expressing this figure on a per hour basis, we obtain the average arrival rate of tows per hour required to attain the total tonnage per year of $P$, that is, equation (4):

$$
\lambda^{*}=\frac{K}{8,760}=\frac{(1+p) P / A}{8,760} .
$$

Table 1 contains the relationship between the arrival rate, $\lambda^{*}$, the percentage utilization of the lock, $\rho$, (to provide an example, a service time $1 / \mu$ of one hour is assumed), and total locking time, $T_{L}$. Note that $T_{L}$ does not begin to rise rapidly until the lock is utilized more than 50 per cent of the time; it begins to rise very rapidly at a utilization rate of about 80 per cent.

For any $K$, adding another tow to the waterway would result in higher utilization of the lock and greater waiting time. The amount of added queuing time is spread across all existing tows, and the increase in $T_{L}$ appears to be quite small. Nonetheless, the addition of one extra tow can give rise to a substantial increase in queuing time in total.

Also given in Table 1 is $\tau=K T_{L}$, the total locking time for all tows during the year. The increase in total locking time due to an extra tow is given in equation (5) and shown in the table.

$$
\frac{\partial \tau}{\partial K}=\frac{\partial[8,760 K /(8,760 \mu-K)]}{\partial K}=\left(\frac{8,760}{8,760 \mu-K}\right)^{2} \mu .
$$

Note that $\partial \tau / \partial K$ rises very rapidly as percentage utilization rises.

In the short run, no tow should be allowed on the waterway unless it earns at least $(\partial \tau / \partial K) V$ (per hour) in profit (where $V$ is the hourly cost of keeping a tow waiting). If additional tows wanted to use the waterway, they should be admitted only if they earned a rate of profit as great as the new higher $(\partial \tau / \partial K) V$ that they would cause. In addition, some existing tows should now be denied entry if they could not meet the new profitability level-the new $(\partial \tau / \partial K) V$. 
TABLE 1

\begin{tabular}{|c|c|c|c|c|c|c|c|}
\hline$K$ & & $\rho=\frac{100 \lambda^{*}}{\mu}$ & $T_{L}$ & $\tau$ & $\frac{\partial \tau}{\partial K}$ & $\Theta$ & $-\frac{\partial \tau}{\partial \mu}$ \\
\hline 1. & & 0.01 & 1.00 & 1 & 1.00 & 0.00 & 1 \\
\hline 100. & & 1.14 & 1.01 & 101 & 1.02 & 0.01 & 102 \\
\hline 1,000 . & & 11.40 & 1.13 & 1,129 & 1.28 & 0.15 & 1,280 \\
\hline 2,000 . & & 22.90 & 1.30 & 2,592 & 1.69 & 0.39 & 3,380 \\
\hline 2,190 . & & 25.00 & 1.33 & 2,920 & 1.77 & 0.44 & 3,876 \\
\hline 3,000 . & & 34.30 & 1.52 & 4,563 & 2.31 & 0.79 & 6,930 \\
\hline 4,000 . & & 46.70 & 1.84 & 7,361 & 3.39 & 1.55 & 13,560 \\
\hline 5,000 . & & 57.10 & 2.33 & 11,648 & 5.43 & 3.10 & 27,150 \\
\hline 6,000 & & 68.50 & 3.18 & 19,043 & 10.11 & 6.93 & 60,660 \\
\hline 7,000 & & 80.00 & 4.98 & 34,841 & 24.80 & 19.82 & 173,600 \\
\hline 8,000 . & & 91.40 & 11.52 & 92,210 & 132.71 & 121.19 & $1,061,680$ \\
\hline 8,750 . & & 99.90 & 876.00 & 766,500 & 767,376 & 766,500 & $6,714,548,000$ \\
\hline
\end{tabular}

Notes. - $\mu$ : average number of tows serviced per hour by the lock (to illustrate the calculation, $\mu$ is assumed equal to unity).

$K$ : number of tows serviced per year; $\lambda^{*}$ is the number of tows serviced per hour.

$\rho$ : utilization rate of lock (the lock is operating $\rho$ per cent of the time); $\rho / 100=K /(8,760 \mu)=\lambda^{*} / \mu$.

$T_{L}$ : average locking time (including waiting time) in hours. $T_{L}=8,760 /(8,760 \mu-K)=1 /\left(\mu-\lambda^{*}\right)$.

$\tau$ : total locking time per year for all tows in hours. $\tau=K T_{L}=8,760 K /(8,760 \mu-K)=8,760 \lambda^{*} /$ $\left(\mu-\lambda^{*}\right)=K /\left(\mu-\lambda^{*}\right)$.

$\partial \tau / \partial K$ : marginal locking time; the change in total locking time due to the addition of a tow. $\partial \tau / \partial K=$ $[8,760 /(8,760 \mu-K)]^{2} \mu=T_{L}^{2} \mu$.

$\partial \tau / \partial \mu$ : marginal locking time; the change in total locking time due to an increase in the service rate of the lock. $\partial \tau / \partial \mu:-[8,760 /(8,760 \mu-K)]^{2} K=-T_{L}^{2} K$.

$\Theta:(\partial \tau / \partial K)-T_{L}^{2} . \Theta V$ is the optimal toll (where $V$ is the hourly cost of keeping a tow waiting); this toll equates private cost and social cost.

\section{Equating Private to Social Cost}

How might the above analysis be put into practice? One can hardly imagine a government agency attempting to determine whether a particular tow is earning a high enough rate of profit (per hour) to justify its using the waterway. Instead, one might rely on a system of taxes and subsidies.

One way of getting barge operators to use social cost as their guide is to impose a tax equal to the difference between social and private cost. When the decision is whether a tow should be added, social cost is $\partial \tau / \partial K$, while the operator experiences a private cost equal to the average locking time, $T_{L}$. Thus, the optimal tax should be $\Theta V$, as shown in equation (6). ${ }^{9}$ Alternatively, operators might be offered $\Theta V$ as a subsidy to remove a tow.

$$
\Theta V=\left(\frac{\partial \tau}{\partial K}-T_{L}\right) V
$$

The congestion on a waterway could be decreased with substantial savings ensuing if a tow were persuaded to exit. If all operators were polled, they should be willing to pay $\Theta V$ for the tow to exit. Alternatively,

${ }^{9}$ This toll is similar to that calculated by Strotz (1965) under conditions where expansion is impossible. 
each tow should be charged a like amount for staying. Each tow on the waterways is costing all other users @hours; rational allocation of resources requires that a tow not be operated unless it generates at least $\Theta V$ profit.

\section{Long-Run Optimization}

In the long run, the size of the lock ought to be adjusted to reflect the level of operation. Equation (7) defines $\partial \tau / \partial \mu$ which measures the change in total waiting time as the service rate is changed.

$$
\frac{\partial \tau}{\partial \mu}=-\left(\frac{8,760}{8,760 \mu-K}\right)^{2} K
$$

For long-run optimization, the lock should be expanded until the cost of keeping a tow waiting one hour $(V)$ equals the cost (expressed on an hourly basis) of expanding the lock to save that hour. Hence, the lock should be expanded ( $\mu$ increased by $\epsilon$ ) if $(-\partial \tau / \partial \mu) V$ exceeds the cost of increasing the service rate $(\mu)$ by $\epsilon$.

A calculation based on equation (7) is strictly accurate only for infinitesimal changes in lock size. An alternative method of determining when and how much to expand a lock is based on the change in total locking time. This method has the advantage of being accurate for finite changes in lock size. The benefit of expanding a lock is the reduction in total locking time (for all tows), assuming $K$ is fixed. If $T_{L}(K)$ is the average locking time per tow before expansion, $T_{L}^{*}(K)$ is the average locking time after expansion, and $V$ is the hourly cost of keeping a tow waiting, then the benefit of expansion is shown in equation (8) as the total reduction in locking time (for all tows) multiplied by the hourly cost of a tow. ${ }^{10}$ The lock should be expanded as long as $B$ exceeds the annual cost of expansion.

$$
B=\left[T_{L}(K)-T_{L}^{*}(K)\right] K V .
$$

This benefit calculation has been carried out under the assumption that demand (number of trips) is fixed. On the contrary, one would expect an increase in the number of trips after expansion due to the reduction in cost (resulting from a drop in $T_{L}$ and $\partial \tau / \partial K$ ). A consumer surplus argument might be used to calculate the additional benefit stemming from this increase in tonnage. Let $K_{0}$ be the number of trips before expansion and $K_{1}$ be the number of trips after expansion. Then $T_{L}^{*}\left(K_{0}\right)$ is the new average locking time per tow for $K_{0}$ trips and $T_{L}^{*}\left(K_{1}\right)$ is the average locking time for $K_{1}$ trips. Then the additional benefit from this increase in trips could be approximated by $B^{*}$ in equation (9) as one-half the product of the change

\footnotetext{
${ }^{10}$ Equation (8) provides an exact statement of the benefit of expansion (assuming demand is constant). Approximate measures can be derived from the reduction in the toll collected $\left[V\left(\Theta-\Theta^{\prime}\right) K\right]$ or from $(\partial \tau / \partial \mu) V$.
} 
in total locking time and the increase in demand $(K)$ that caused it (multiplied by the hourly cost of a tow):

$$
B^{*}=\left[T_{L}\left(K_{0}\right)-T_{L}^{*}\left(K_{1}\right)\right] \frac{1}{2}\left(K_{1}-K_{0}\right) V .
$$

\section{Lock Expansion: An Example of a Benefit-Cost Analysis}

Given the equilibrium determined by each firm acting independently and assuming demand is fixed, one might perform a benefit-cost analysis on the advisability of expanding the lock. To illustrate the calculation, suppose that tows require, on average, five hours to pass a lock $\left(T_{L}=5\right)$. From equation (4) one can calculate the arrival rate $\left(\lambda^{*}\right)$ to be 0.8 tows per hour (assuming the service rate $(\mu)$ is one tow per hour). Under these conditions, seven thousand tows per year would be serviced by the lock, and the lock would be in operation 80 per cent of the time. A total of 35,000 tow-hours are being spent in locking service each year.

Each tow-hour represents a cost of between one and two hundred dollars. Thus, between $\$ 3.5$ and $\$ 7$ million are spent in waiting for lock service each year. If the service rate of the lock could be doubled, the total service time would drop from 5 hours to 0.83 hour (assuming that the quantity demanded remains fixed). On average, 4.17 hours per tow would be saved, and the annual benefit would amount to $\$ 2.9$ to $\$ 5.8$ million. The annual cost of lock expansion has been estimated to be between $\$ 625,000$ and $\$ 1,663,000 .{ }^{11}$ Here, the benefits exceed the costs by a vast amount, and expanding the lock would improve over-all efficiency. ${ }^{12}$

At present, no toll is charged for passing a lock. Under these conditions, this sort of benefit-cost analysis would not lead to a social optimum but only to a second-best solution. The solution is optimal, given that tow owners use $V T_{L}$ in their decision to add a tow; a better solution would result if tow owners used $V \partial \tau / \partial K$ to guide their decision. That is, the above solution is optimal given that tow owners use private rather than social costs to guide their decisions, but the solution could be improved by relaxing the constraint. ${ }^{13}$

It is possible to characterize the way in which this second-best solution deviates from Pareto optimality. The imposition of a toll (which is necessary to achieve efficiency) would decrease the quantity of waterway carriage demanded. A benefit calculation, based on equation (8), would indicate the need for less expansion. Constructing fewer locks would lessen government expenditures (and, presumably, taxes). Thus, the failure

${ }^{11}$ See the U.S. Army Engineers Report (1957).

${ }^{12}$ The distribution of the entire locking process, waiting plus service, will be Poisson with parameter $1 /\left(\mu-\lambda^{*}\right)$. If $K$ tows are serviced each year, the mean number of hours spent in locking would be $K /\left(\mu-\lambda^{*}\right)$ with variance $1 /\left(\mu-\lambda^{*}\right)$.

${ }^{13}$ Note that if demand was constant (the demand curve was vertical) the above solution would be first best rather than second best. 


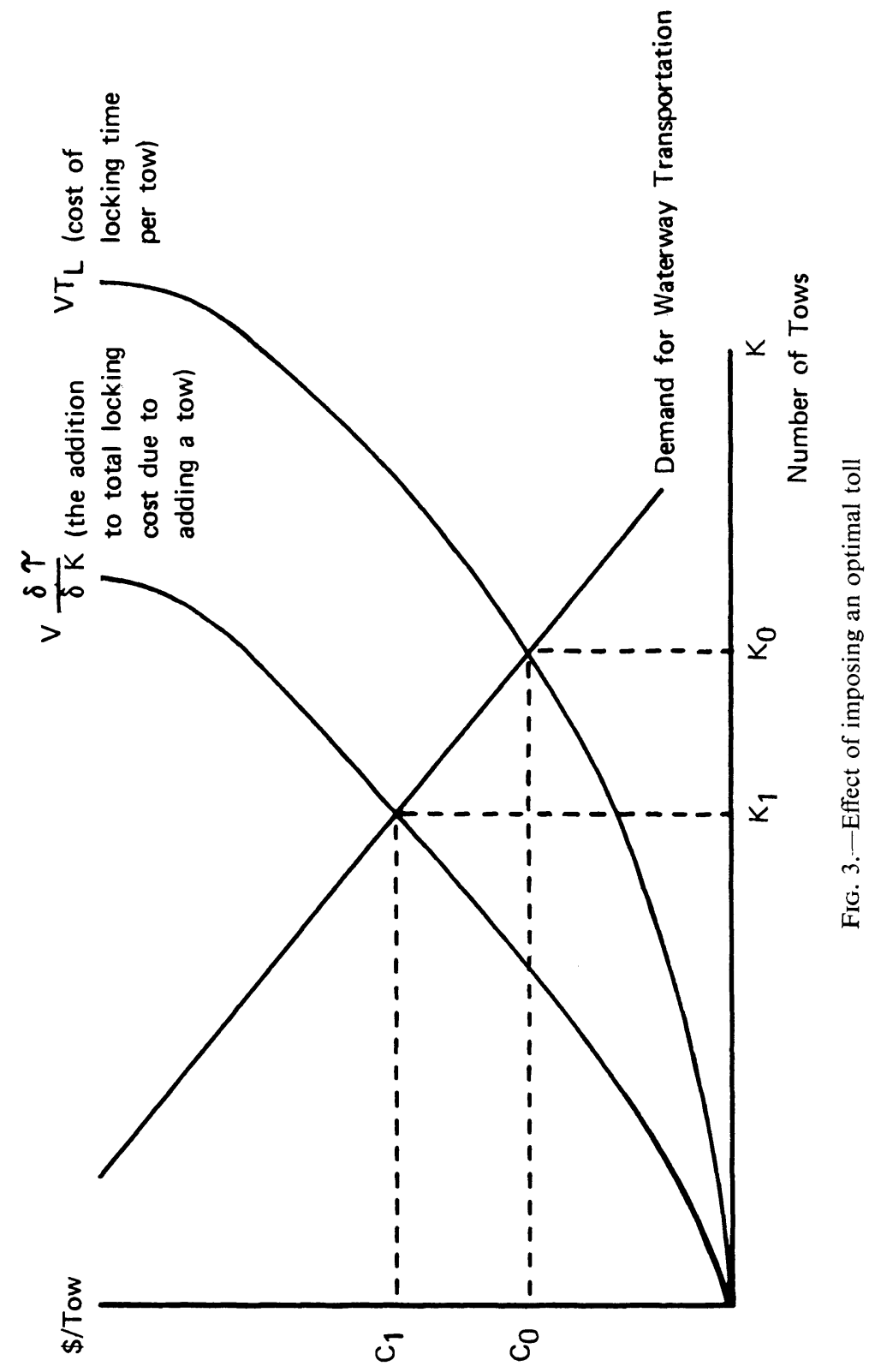


to impose tolls results in an income transfer from tax payers to waterway carriers and their shippers. There is evidence that waterway transportation is a purely competitive industry, and so one would conclude that the absence of tolls gives rise to a subsidy to those firms which ship on inland waterways.

Shipper groups and carriers strongly oppose the imposition of tolls. Two reasons might be given to explain this opposition. The first is that, except by chance, revenue from an optimal toll will not equal the cost of lock expansion. While establishing a toll to promote short-run efficiency does affect long-run efficiency (through the calculation of benefits), the revenue from tolls would be expected to exceed the cost of lock expansion. ${ }^{14}$

The second reason for explaining why carriers oppose tolls has to do with short-run equilibria. This argument is more subtle since tolls are designed to improve the efficiency of short-run equilibria. If an optimal toll were imposed, the cost (to carriers) of using the waterway would increase. The cost to carriers of using the waterway before the toll is simply $V T_{L}$. This cost is a function of $K$, the total amount of traffic, and might be shown in Figure 3 (a smoothed, continuous version of Figure 1, with time converted into money). For any level of traffic, $K$, imposing a toll has the effect of increasing the cost to the carriers; in paying the toll, the carrier must pay social cost $V(\partial \tau / \partial K)=V T_{L}+V \Theta$. The cost to the carrier under an optimal toll scheme, $V(\partial \tau / \partial K)$, is also shown in Figure 3. As long as the demand curve for waterway transportation is negatively sloped, the imposition of tolls must cause the cost to carriers to rise (from $C_{0}$ to $C_{1}$ ) and traffic to fall (from $K_{0}$ to $K_{1}$ ). Thus, the imposition of tolls would drive marginal carriers out of business and raise the cost to carriers who managed to stay in business.

There is one possibility for winning approval of a toll from most carriers. The carriers who remained in business could be placated by returning the toll as a lump sum subsidy. Returning the toll would not affect the social efficiency of the solution and might win the approval of all non-marginal carriers. However, in general it seems evident that shippers and carriers are acting in their own best interest in opposing tolls. ${ }^{15}$

${ }^{14}$ See Strotz (1965) for this point. One might note also that if changes in the service rate are increasingly costly to achieve, toll receipts would more than pay for the lock expansion. Davis and Whinston (1967) affirm this conclusion in analyzing television as a "slightly impure public good."

${ }^{15}$ An air pollution example might clarify this point. Consider a group of smokers meeting in a small, unventilated room. Shortly, the polluted air would cause all to agree that smoking should be restricted. Since all are smokers, all are responsible for the pollution. Yet, if each were to act independently, each would have a small enough effect on pollution that he would maximize his private utility by continuing to smoke. The private benefit from smoking leads to a social cost of foul air. A tax per cigaret smoked could be used to bring private and social costs into line. At some point, the air would become sufficiently polluted to cause most smokers to vote for regulation. This tax need not even be collected if people were put "on their honor not to smoke a cigaret unless they were willing to pay for it." If the tax were collected, it would be 


\section{Tolls and Tow Size}

The possibility of increasing tow size implies that $\Theta V$ need not be the optimal toll to achieve short-run efficiency. This toll is levied on any tow that passes a lock. Since it does not depend on tow size, it discriminates in favor of larger tows. Because it leads to larger tows, this toll would lead to greater service rates and require the analysis to be modified. The toll should be based on the service time of a tow, since it is this time which is relevant for determining congestion. If $\Theta$ were calculated on the basis of an average service time of $1 / \mu$, each tow should be charged a toll of $V \Theta / \mu$ for each hour of service time at the lock. ${ }^{16}$

With a toll based on service time, one would expect to see tows of one efficient size (or possibly two). The most efficient size for a tow (from the viewpoint of lock efficiency) can be determined by assuming that demand ( $\delta$ barges must be served each year) is fixed. Note that $V(b)$, the hourly cost of a tow, is a function of its size. The number of barges in a tow is $b$, so the number of tows must be $K=\delta / b$. Total locking time each year is $\tau$, and the cost of this locking time is $\tau V$. We wish to minimize the cost of total locking time by optimizing the number of barges in a tow.

$$
\begin{aligned}
\tau V & =V K T_{L}=\frac{V K}{\mu-\frac{K}{8,760}}=\frac{\delta}{b} \frac{V}{\mu-\frac{\delta}{b 8,760}}=\frac{\delta V}{b \mu-\frac{\delta}{8,760}} ; \\
\frac{\partial \tau V}{\partial b} & =\frac{\delta V^{\prime}}{b \mu-\frac{\delta}{8,760}}+\frac{\delta V\left(-\mu-b \mu^{\prime}\right)}{\left(b \mu-\frac{\delta}{8,760}\right)^{2}}
\end{aligned}
$$

much easier to secure support for it if it were to be returned as a lump sum subsidy later.

In deciding whether to instal a ventilator, the amount of tax revenue would have little information content. Furthermore, as in the case of the waterway, the tax would be greatest before the ventilator. If there were decreasing costs in ventilation, receipts would be less than costs; for constant costs they would be equal, and for increasing costs receipts would exceed costs. Thus, there seems to be little sense in tying ventilator costs to tax revenues.

This situation (where the externality is confined to the group who causes it) arises in both waterways and airports. The more conventional externality case has the externality borne by a group that has nothing to do with its creation, for example, urban air pollution. If this externality were positive, it would be an example of the rationale behind Marshall's "forward falling supply curve."

${ }^{16}$ Continuing the analogy with airports, one should expand service facilities (the number of runways) when the cost of time saved exceeds the cost of expansion. Since airplanes require different amounts of time to take off or land, there should be different fees which depend on service time. (Where landing fees exist, they are fixed per landing or per number of passengers landed. Since the larger airplanes land more rapidly, these fees tend to encourage inefficiency.) Since current landing fees are only token or are non-existent, airlines and air travelers are being subsidized. Finally, note that airlines pay little or none of the cost of expansion, so it pays them to overstate the amount of congestion. 
where

$$
V^{\prime}=\frac{d V}{d b}
$$

and

$$
\begin{aligned}
\mu^{\prime} & =\frac{d \mu}{d b} \\
\frac{\partial \tau V}{\partial b} & =\frac{\delta}{\left(b \mu-\frac{\delta}{8,760}\right)^{2}}\left(V^{\prime} b \mu-\frac{V^{\prime} \delta}{8,760}-V \mu-V b \mu^{\prime}\right)=0 ;
\end{aligned}
$$

or

$$
b=\frac{V \mu}{V^{\prime}\left(\mu-\lambda^{*}\right) V \mu^{\prime}} .
$$

In the special case where tow cost does not depend on tow size $\left(V^{\prime}=0\right)$, the optimal tow size is given in equation (11):

$$
b=-\frac{\mu}{\mu^{\prime}}
$$

when $V^{\prime}=0$. Thus, the most efficient tow size is that which minimizes locking time per barge or, equivalently, the size where average service time equals the marginal service time. ${ }^{17}$ This case is illustrated in Table 2, assuming that 87,600 barges must be served each year. This demand could not be filled if tow size were as small as five barges or as large as twenty barges. For this illustration, the optimal size tow is fifteen barges, with an

\begin{tabular}{|c|c|c|c|c|c|c|c|c|}
\hline & $b$ & & $\mu$ & $K=(87,600 / b)$ & $\lambda^{*}$ & $T_{L}$ & $\tau$ & $T_{L} / b$ \\
\hline 1 . & • & . & 3 & 87,600 & 10 & $\infty$ & $\infty$ & $\infty$ \\
\hline 5. & . & . & 2 & 17,520 & 2 & $\infty$ & $\infty$ & $\infty$ \\
\hline 10. & 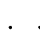 & . & $\frac{4}{3}$ & 8,760 & 1 & 3 & 26,280 & 0.30 \\
\hline 15. & 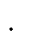 & . & 1 & 5,840 & $\frac{2}{3}$ & 3 & 17,520 & 0.20 \\
\hline 20. & . & . & $\frac{1}{2}$ & 4,380 & $\frac{1}{2}$ & $\infty$ & $\infty$ & $\infty$ \\
\hline
\end{tabular}
average locking time of three hours and a locking time per barge of one-fifth of an hour.

TABLE 2

The Effect of Tow Size on Total Locking Time

NOTES.- $b$ : number of barges in a tow.

$\mu$ : number of tows that can be served by the lock each hour.

$K$ : number of tows; equal to the number of barges to be moved divided by the number of barges per tow.

$\lambda^{*}$ : number of tows arriving each hour at the locks.

$T_{L}$ : total locking time (waiting plus service) per tow.

$\tau$ : total locking time for all tows.

$T_{L} / b$ : locking time per barge.

${ }^{17}$ When the cost of a tow increases with its size $\left(V^{\prime}>0\right)$, tow size will be smaller than when $V^{\prime}=0$ (and $K$ will be larger). 


\section{An Application: The Illinois Waterway}

An example might serve to clarify this analysis. A recent study was undertaken to determine whether lock capacity on the Illinois waterway should be expanded (U.S. Army, 1957). It was proposed that a second lock, twice the size of the existing one, be installed parallel to the old lock at each of the seven existing structures. It is assumed that the installation of this second lock would double the service rate. It is possible that the service rate might be more or less than doubled since the narrowness of the channel means that both locks would experience restricted operations (physical lock capacity actually triples under this plan). The study developed an annual cost for the lock expansion which averaged $\$ 656,000$ for each of the seven locks on the Illinois waterway.

Suppose there were a single lock on the waterway and that the cost of keeping a tow waiting is $\$ 100$ per hour. Then the lock should be improved if at least 6,500 tow-hours can be saved per year. Such a savings would be obtained if $K=5,000$. For this number of trips, the average locking time $T_{L}$ would be 2.33 hours at the old service rate of $\mu=1$ per hour. At the new service rate of two tows per hour, $T_{L}$ would be 0.69 hour. The improvement results in a saving of 8,200 tow-hours per year as calculated in equation (12):

$$
B=(2.33-0.69) 5,000 \mathrm{~V}=8,200 \mathrm{~V}=\$ 820,000 .
$$

Since the saving, $\$ 820,000$, exceeds the cost, it would pay to expand the lock capacity when the utilization rate is approximately 57 per cent. The calculation is shown in Table $3 .{ }^{18}$

TABLE 3

The Benefit of Lock Expansion

\begin{tabular}{|c|c|c|c|}
\hline$K$ & $T_{L}(K)$ & $T_{L}^{*}(K)$ & $B=V K \Delta T_{L}$ \\
\hline 3,000 & 1.521 & 0.363 & $\$ 347,200$ \\
\hline 4,000 & 1.840 & 0.415 & 568,100 \\
\hline 5,000 & 2.327 & 0.690 & 819,800 \\
\hline
\end{tabular}

Notes. $-K$ : number of tows serviced per year; $T_{L}(K)$ : total locking time (waiting plus service) per tow; $T_{L} *(K)$ : total locking time per tow, assuming the service rate $(\mu)$ has doubled; $B$ : the estimated benefit of lock expansion (assuming demand is fixed).

${ }^{18}$ In this calculation, it is assumed that demand is fixed since no estimate of the price elasticity of demand was available. Probably the best estimate of when to expand capacity in this example would be at about 50 per cent of capacity. An independent check of the reasonableness of this figure is provided by the analysis of Bottoms (1966). Bottoms assumes that half of the barges will be empty $\left(p=\frac{1}{2}\right)$ and concludes that the "practical" capacity of a waterway is about 25 per cent of the tonnage that could be moved if all barges were full and there was always a tow waiting to be served. Using the same $p$, our conclusions are identical. 
One might also determine the optimal toll in this example. This toll should be the difference between social and private cost, $\Theta V$. Before the improvement was made, $K=5,000$ implies that the time penalty imposed by the marginal tow is 3.10 hours, which implies a toll of $\$ 310$. After the service rate is doubled, the time penalty is 0.27 hour, and the toll should be $\$ 27 .{ }^{19}$

This example has been phrased in terms of a single lock. However, as noted above, under the assumptions of the queuing model, locks can be treated independently. If all traffic traverses the entire waterway, the arrival rate at each lock would be identical, and the calculation that justifies one lock expansion would justify expanding all locks. If the arrival rate differs, one must carry out the calculation for each lock.

\section{Summary}

Congestion results from "too many customers." The analysis of congestion becomes complicated when the arrival of customers is random or the service rate is random. In this stochastic case, optimal economic capacity will be far less than physical capacity. When a facility is used by a number of independent customers, there is an externality associated with the decision to use the facility. Social cost (the effect on everyone of adding a customer) is far greater than private cost (that faced by the customer who might demand the service of the facility) in the absence of a tax system or regulatory scheme.

Three questions arise whenever congestion occurs. The first question concerns the optimal use of a facility (the determination of economic capacity). This question might be answered by a system of optimal tolls or subsidies which equate private to social cost. To illustrate the analysis, we calculated the social cost of adding a tow to a waterway, and we determined the toll which would cause the tow operator to face social cost. The second question concerns the decision to expand physical capacity (when is the demand sufficiently large to justify expansion?). This question might be answered by a benefit-cost analysis of the expansion decision. For example, the benefit of expanding a lock is the reduction in total locking time; if this dollar benefit exceeds the cost of expansion, physical capacity should be increased. The third question concerns the effect of a toll (or of its absence) on the character of the service demanded (the amount of service time demanded by a single customer). This question might be answered by noting that congestion results from the amount of service time demanded by a customer. Thus, the optimal toll should depend on actual service time. Since there is an ability to change tow

${ }^{19}$ The toll could have no effect on traffic if demand were constant; thus, charging a toll could not have any effect on resource allocation and would serve only to raise revenue. If demand were not constant and if $K$ were 5,000 tows per year, the tolls would be as calculated. 
size (and thereby change service time), the optimal toll on a waterway should be calculated on the basis of actual service time.

\section{References}

Bottoms, Eric. "Practical Tonnage Capacity of Canalized Waterways," J. Waterways and Harbors Division, Proc. American Soc. Civil Engineers (February, 1966).

Davis, O., and Whinston, A. "On the Distinction between Public and Private Goods," A.E.R. (May 1967).

DeSalvo, J., and Lave, L. "An Analysis of Towboat Delays," J. Transport Econ. and Policy (to be published).

Hunt, Gordon. "Sequential Arrays of Waiting Lines," J. Operations Res. Soc. America (December, 1956).

Morse, Phillip. Queues, Inventories, and Maintenance. New York: John Wiley \& Sons, 1958.

Strotz, R. "Urban Transportation Parables," in J. Margolis (ed). The Public Economy of Urban Communities. Washington, D.C.: Resources for the Future, 1965.

U.S. Army Engineers Division, Chicago District, Interim Survey Report: Duplicate Locks, Illinois Waterway. Washington: U.S. Government Printing Office, January 25, 1957. 